\title{
Development of Remote and Contact Techniques for Monitoring the Atmospheric Composition, Structure, and Dynamics
}

\author{
B.D. Belan, Yu. S. Balin, V.A. Banakh, V.V. Belov, V.S. Kozlov, \\ A.V. Nevzorov, S.L. Odintsov, M.V. Panchenko and \\ O.A. Romanovskii
}

\begin{abstract}
Prototypes of a typical automated station for monitoring the atmospheric composition and state, as well as lidars and sodars, have been designed and manufactured within the project, which are to be the components of monitoring stations. Experimental tests of the instruments confirmed their designed-in specifications and functions. For contact measurements of air parameters, a complex air monitoring station and an aerosol multiwave diffusion spectrometer have been also designed and manufactured in accordance with technical assignment requirements. The measurement results have shown a continuous increase in the concentrations of
\end{abstract}

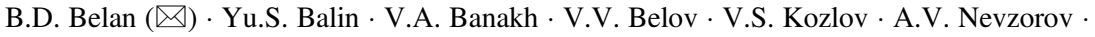

S.L. Odintsov · M.V. Panchenko · O.A. Romanovskii ( $\bowtie)$

V.E. Zuev Institute of Atmospheric Optics SB RAS, Tomsk, Russia

e-mail: bbd@iao.ru

O.A. Romanovskii

e-mail: roa@iao.ru

Yu.S. Balin

e-mail: balin@iao.ru

V.A. Banakh

e-mail: banakh@iao.ru

V.V. Belov

e-mail: belov@iao.ru

V.S. Kozlov

e-mail: vkozlov@iao.ru

A.V. Nevzorov

e-mail: nevzorov@iao.ru

S.L. Odintsov

e-mail: balin@iao.ru

M.V. Panchenko

e-mail: pmv@iao.ru

(C) The Author(s) 2018 
carbon dioxide and nitrous oxide, as well as a renewed increase in the methane concentration in the layer from 0 to $7 \mathrm{~km}$.

Keywords Atmosphere - Greenhouse gases - Aerosols • Laser sensing Lidar · Continuous in-situ measurements · Monitoring $\cdot$ Aircraft laboratory Satellite sounding · Sodar

\section{Introduction}

There is no proper network for complex air monitoring in Russia today, which covers the whole territory and answer modern requirements. The existing network of the Russian Hydrometeorological Service (Roshydromet) provides only hydrometeorological information and data on urban air pollution. However, these data alone are insufficient in the modern context, even despite the Roshydromet network density. Monitoring of the atmospheric composition, structure, and dynamics does not require such a dense network; however, the requirements for the equipment of the network stations are much higher. Thus, the new-generation Integrated Carbon Observation System (ICOS) [1] was recently created in Europe. This system was initially planned to be used for monitoring of only greenhouse gases on the basis of complex gradient measurements at tall masts (towers) and air sampling for the analysis with the usage of light airplanes. However, while developing the system, it became clear that this is insufficient. Since the atmosphere is a global chemical reactor and permanently interacts with the underlying surface, much more atmospheric admixtures are required to be measured, as well as their fluxes from the Earth's and ocean surfaces by both local and remote monitoring means.

All the works scheduled within the project can be divided into three directions.

1. Development and creation of new techniques and devices and improvement of processing algorithms.

1.1. Design of a typical automated station for monitoring the atmospheric composition and state.

1.2. Design and manufacturing of a diffusion spectrometer.

1.3. Design of scanning polarization lidar "LOSA-M3".

1.4. Design of the prototype of "Aerosol-3" lidar.

1.5. Design of the prototype of "ST Ozon" lidar.

1.6. Design of a multifrequency three-channel sodar.

1.7. Development of algorithms for estimation of the wind speed and direction from lidar data.

1.8. Development of algorithms for atmospheric correction of satellite images.

2. Metrological examination of the devices designed.

3. Continuation of the monitoring at existing stations and setups. 
The aim of the project is the development of new techniques for monitoring the atmospheric composition, structure, and dynamics and design of new instruments, their metrological examination, and continuous measurements of currently operating systems for extension of long-term observation series.

\section{Typical Up-to-Date Automated Station for Monitoring the Atmospheric Composition and State}

The prototype of a monitoring station of atmospheric composition and state has been designed and manufactured. Its block diagram is shown in Fig. 1. The prototype consists of the following main parts: Gas-analysis unit; aerosol unit; actinometric unit; airlines of communications; meteorological unit; and interface, control, and data processing unit.

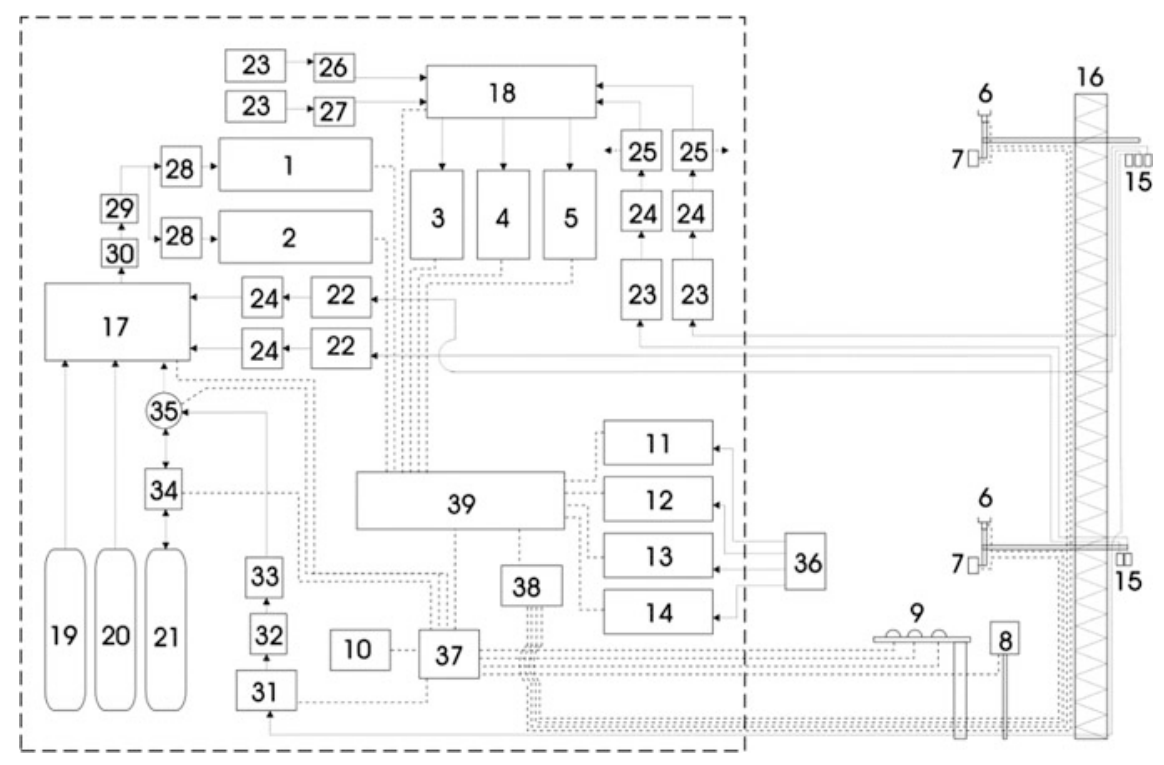

Fig. 1 Block diagram of a typical up-to-date atmospheric composition and state monitoring station: $\mathrm{CO}_{2} / \mathrm{CH}_{4} / \mathrm{H}_{2} \mathrm{O}, \mathrm{CO}, \mathrm{SO}_{2}, \mathrm{NO}_{\mathrm{x}}$, and $\mathrm{O}_{3}$ gas analyzers $(1,2,3,4$, and 5, respectively); ultrasonic anemometers $(6)$; temperature and humidity sensors inside a radiation protective case (7); automated precipitation gauge at a rod (8); pyranometers at actinometric holder (9); atmospheric pressure sensor (10); aerosol diffusion spectrometer (11); optical aerosol spectrometer (12); nephelometer (13); aethalometer (14); air samples (15); truss mast (16); airflow distributors $(17,18)$; tanks filled with calibration gas mixtures (CGM) $(19,20)$; tank filled with a reference gas mixture (RGM) (21); pumps $(22,23)$; water eliminators (24); receivers (25); thermostats with $\mathrm{SO}_{2}$ and $\mathrm{NO}_{2}$ microstream sources $(26,27)$; mass air flow controllers (28); controlling filter (29); cut-off valve (30); compressor (31); Nafion dryer (32); chemical dryer (33); high-pressure sensor (34); three-position electropneumatic distributor (35); aerosol isokinetic sampler (36); control and interface unit (37) UST to RS-232/422/485 converter (38); computer (39). Solid lines with arrow show airline communications; dashed lines, electronic communications 


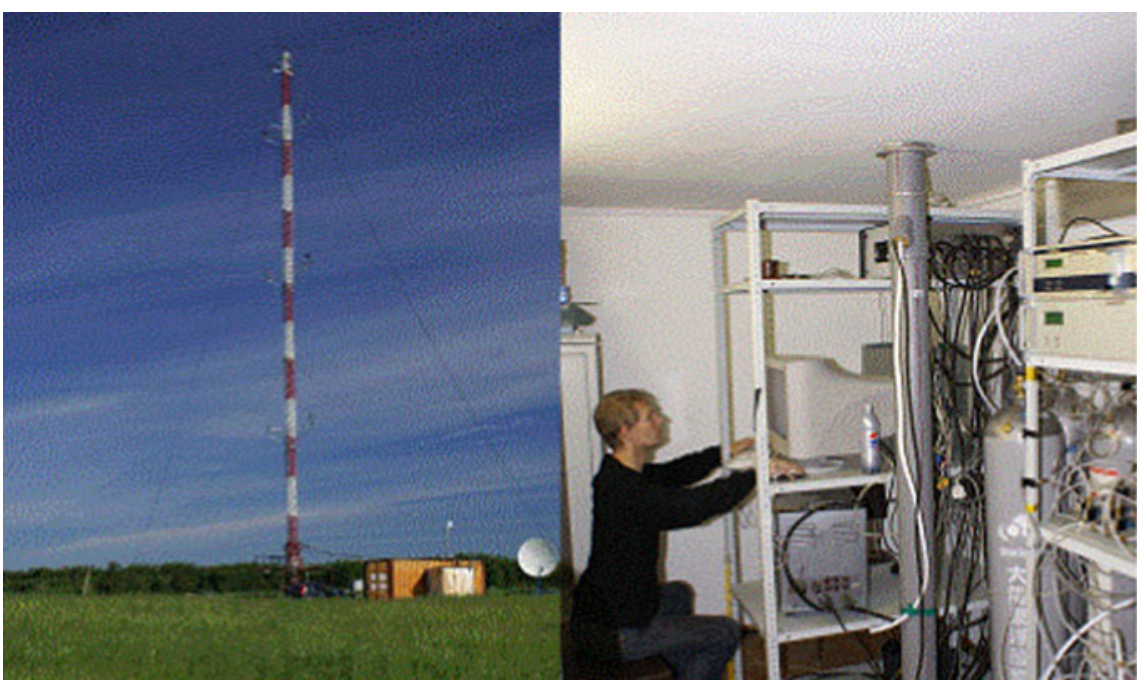

Fig. 2 General view of the experimental site, container and equipment inside it

The following components are provided in the prototype for monitoring trace gases: Greenhouse gas analyzer $\left(\mathrm{CO}_{2}, \mathrm{CH}_{4}\right.$, and $\left.\mathrm{H}_{2} \mathrm{O}\right)(1)$; $\mathrm{CO}$ analyzer (2); gas analyzers for chemically active gases $\left(\mathrm{SO}_{2}, \mathrm{NO}_{x}\right.$, and $\left.\mathrm{O}_{3}\right)(3,4$, and 5, respectively); high-pressure tanks filled with calibration gas mixtures $\left(\mathrm{CO}_{2}, \mathrm{CH}_{4}\right.$, and $\left.\mathrm{CO}\right)(19$ and 20); high-pressure tank filled with a reference gas mixture (21); calibration $\mathrm{SO}_{2}$ and $\mathrm{NO}_{2}$ microstream sources (26 and 27); airflow distributors (17 and 18); and sampling devices $(15,24,25,28,29,30,32,33$, 34, and 35). Main specifications of the prototype are given in [2].

The prototype of an up-to-date station for monitoring the atmospheric composition and state was tested in experiments carried out in the territory of Large Experimental Complex of IAO SB RAS in August 15-30, 2015. The experimental site is shown in Fig. 2.

The experiments performed [2] have shown the complete correspondence of the prototype specifications to the technical assignment.

\section{Aerosol Multiwave Diffusion Spectrometer}

The aerosol (black carbon, BC) multiwave diffusion spectrometer has been designed for the study of absorbing properties of BC-containing atmospheric aerosols, which are generated during numerous natural and anthropogenic combustion processes. The BC diffusion spectrometer allows prompt local control and long-term monitoring of the mass concentration of absorbing matter and its size distribution inside submicron atmospheric aerosol on the basis of recorded signals of light scattered in the visible spectral region by a layer of particles deposited on an aerosol filter. 
Fig. 3 General view of the BC diffusion spectrometer: Pump and airline communication (1), signal USB ports (2); IBM computer with software for data recording and control (3); eight-section diffusion battery (4); MDA-03 multiwave aethalometer (5); FAN-M multiwave nephelometer (6)

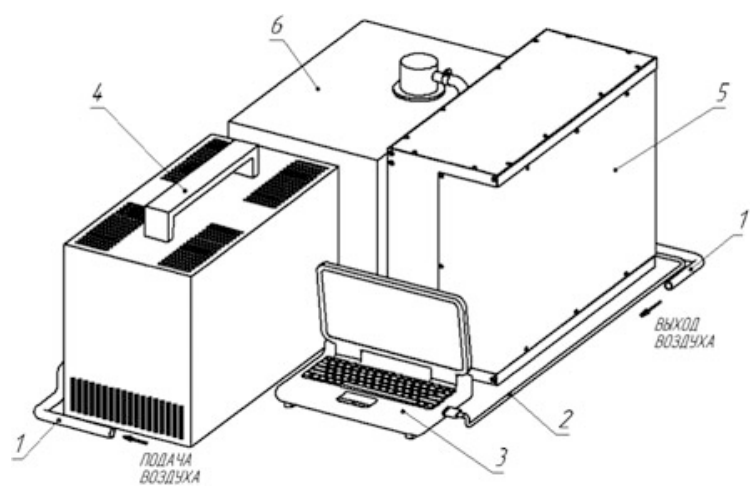

Figure 3 shows the BC diffusion spectrometer. Its specifications are given in [3]. The results of the experimental tests of the $\mathrm{BC}$ diffusion spectrometer in laboratory conditions and in the Large Aerosol Chamber of IAO SB RAS [3] witness that its specifications correspond to the requirements of the technical assignment.

\section{Multiwave Scanning Polarization Lidar "LOSA-M3"}

The LOSA-M3 lidar has been designed for measurements of optical and microphysical parameters of atmospheric aerosol on the basis of the analysis of multiwave lidar observation data [4]. The principle of operation of the lidar is the following: A directed laser pulse at wavelengths of 355, 532, and $1064 \mathrm{~nm}$ is sent into the atmosphere; aerosol-backscattered signal of elastic scattering at unshifted wavelengths and Raman scattering signal from molecular nitrogen at wavelengths of 387 and $607 \mathrm{~nm}$ and from water vapor at $407 \mathrm{~nm}$ are detected by a system of photodetectors, digitized by rapid receivers, and written on the computer. Then the aerosol optical parameters are retrieved on the basis of the signals recorded by the algorithms developed. The LOSA-M3 lidar is shown in Fig. 4.

The use of elastic and Raman scattering signals at several wavelengths allows retrieval of the aerosol optical parameters (attenuation and backscattering coefficients and mass concentration of aerosols in industrial emissions in the case of special calibration).

A transmit-receive unit of the lidar is assembled on a frame, where a laser with a collimator, near- and far-field receiving lenses, photodetectors, and a separate polarization receiver are mounted. The transmit-receive unit is mounted on a scanning rotating rod, which allows the lidar scanning in vertical and horizontal planes.

Figure 5 shows the lidar measurement results in the period of experimental tests of the prototype of the LOSA-M3 multiwave scanning polarization lidar at the IAO SB RAS test area in autumn 2015. The test of the LOSA-M3 lidar showed its correspondence to the requirements of the technical assignment. 


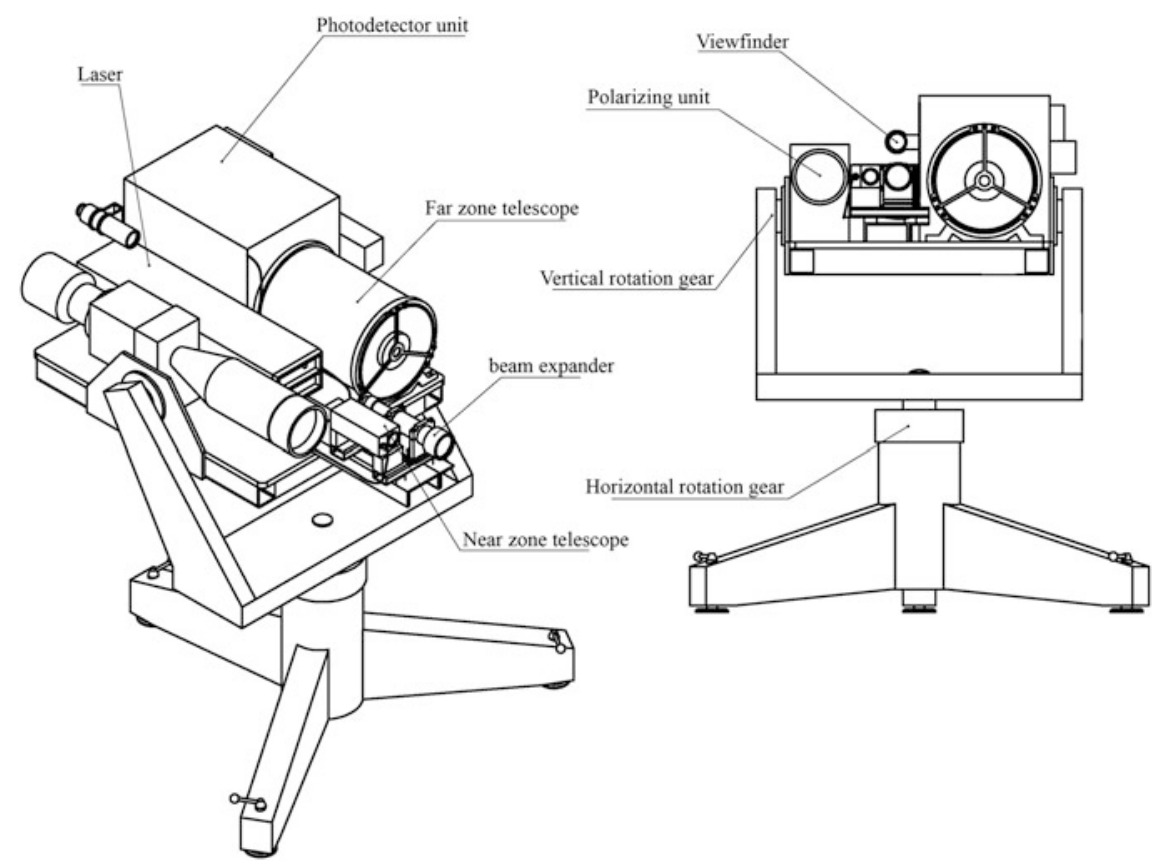

Fig. 4 LOSA-M3 lidar
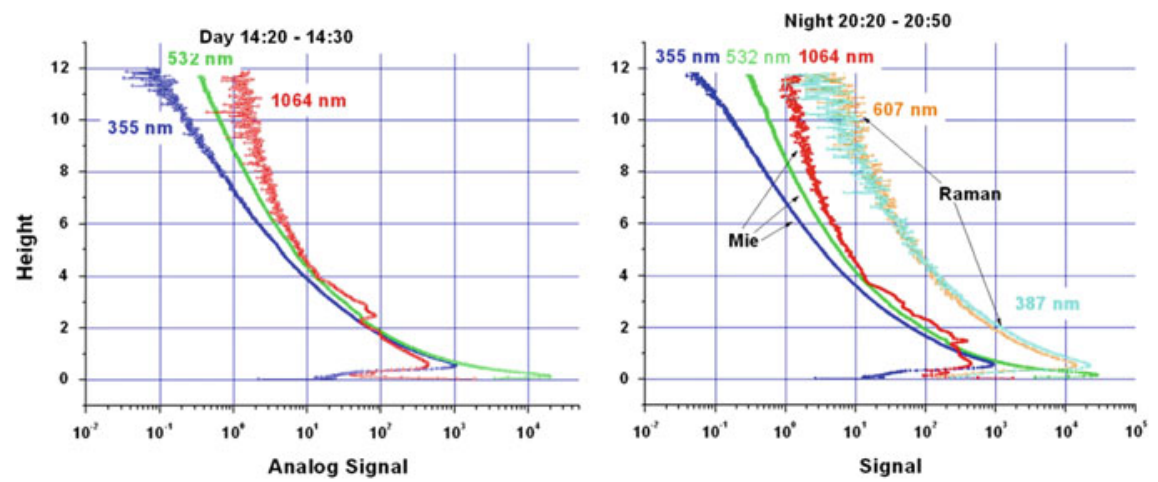

Fig. 5 Aerosol and Raman scattering signals in day- and nighttime

\section{“Aerosol-3" Lidar}

The Aerosol-3 lidar has been designed for measurements of optical and microphysical parameters of atmospheric aerosol on the basis of the analysis of multiwave lidar observation data. The lidar operates in the following way: A directed laser pulse at wavelengths of 355,532 , and $683 \mathrm{~nm}$, which correspond to the third 
and second harmonic of an Nd:YAG laser and the first Stokes component of the $532 \mathrm{~nm}$ radiation conversion in hydrogen on the basis of stimulated Raman scattering (SRS) is sent into the atmosphere. The above wavelengths are implemented in one coaxial beam from one radiation source. This strongly simplifies the adjustment and operation of the three-frequency lidar and allows measurements in the routine mode.

The block diagram of the Aerosol-3 lidar designed is shown in Fig. 6.

During experiments, a sounding beam is directed to a flat roof of the Siberian Lidar Station (SLS) of IAO SB RAS parallel to the surface with the use of a rotating mirror. A roofed tunnel $1 \mathrm{~m}$ diameter and $6 \mathrm{~m}$ long is mounted at the roof edge. The tunnel is equipped with instruments that ensure creation of an aerosol cloud of a required density inside the tunnel and measure optical and microphysical parameters of the aerosol (scattering, extinction, and backscattering coefficients; particle radius, and volume concentration). Lidar measurements were carried out in

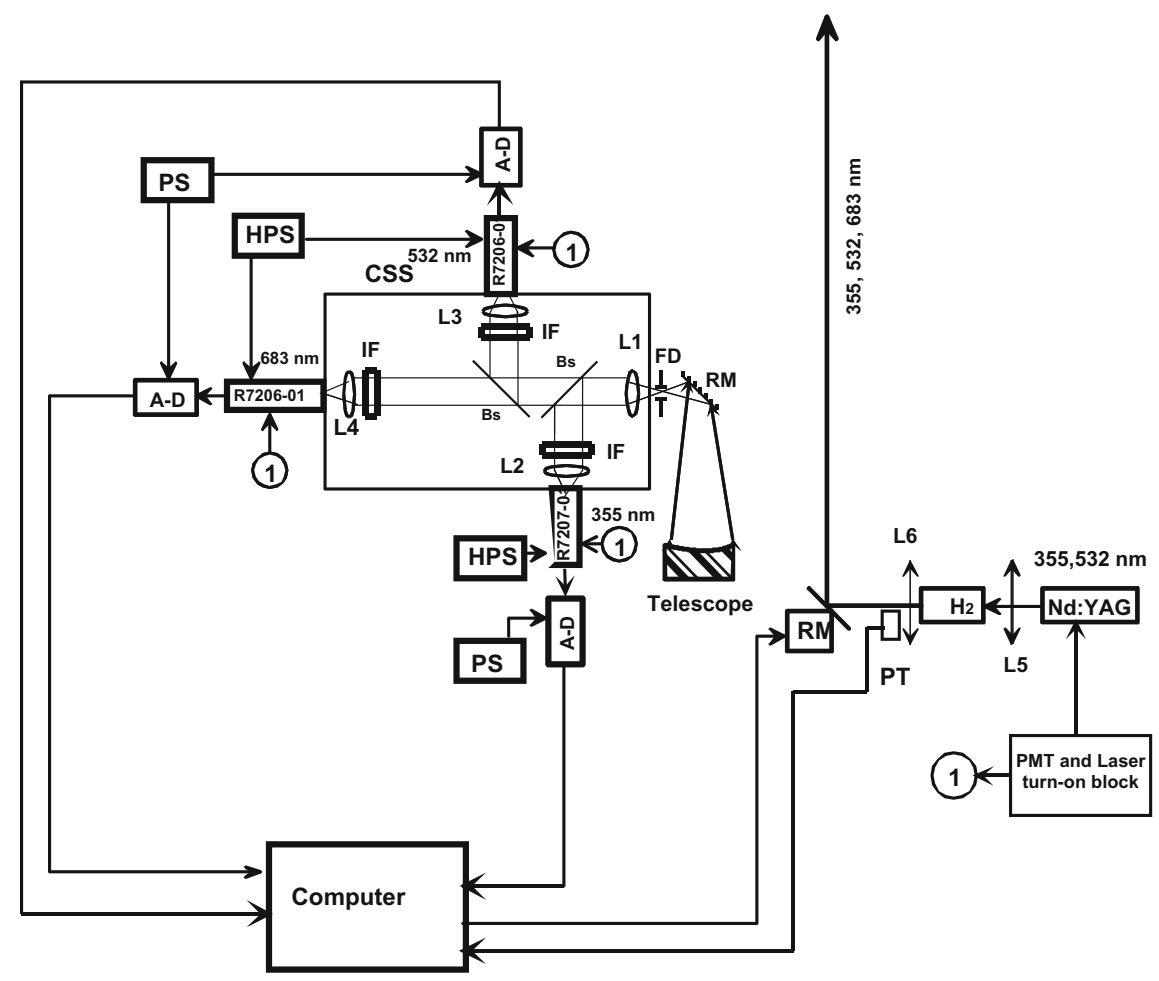

Fig. 6 Block diagram of the aerosol-3 three-wavelength lidar for stratospheric aerosol sounding: Solid-state laser (Nd:YAG), SRS conversion cell with $\mathrm{H}_{2}\left(\mathrm{H}_{2}\right)$, automated rotating mirror (RM), field stop (FS), spectral selection cell with a PMT (SSC), lenses (L), spectral line divider (SD), interferences filters (IF), amplifiers/discriminators (AD), power supplies (PS), high-voltage power supplies (HSU), optical transistor for photon counter actuation (OT) 
Fig. 7 Elastic backscattering signals recorded at SLS in nighttime on June 13, 2016

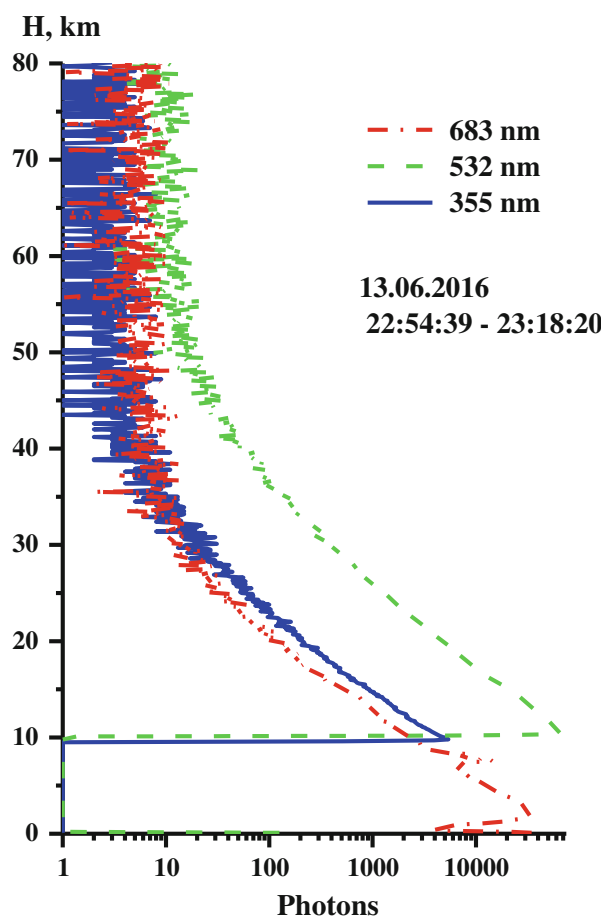

summer of 2016. Figure 7 shows the elastic backscattering signals recorded in the night time.

The experimental examination of the Arosol-3 lidar has shown the correspondence to the requirements of the technical assignment.

\section{"ST Ozon" Lidar}

The ST Ozon lidar has been designed for the study of ozone dynamics near the tropopause and stratospheric-tropospheric exchange in the upper tropospherelower stratosphere. Figure 8 shows the block diagram of the lidar manufactured.

The fourth harmonics $(266 \mathrm{~nm})$ of the fundamental frequency of an $\mathrm{Nd}$ :YAG laser (LS-2134UT laser, LOTIS TII company, Minsk) is used as a laser radiation source, which is then SRS converted in hydrogen in the first $(299 \mathrm{~nm})$ and second $(341 \mathrm{~nm})$ Stokes components. During the experimental examination of the prototype of ST Ozon lidar at SLS of IAO SB RAS in summer of 2016, the lidar signals at 299/341 nm sounding wavelengths have been recorded in nighttime. They are shown in Fig. 9, as well as the ozone vertical profile retrieved from them. The experimental examination of the Arosol-3 lidar prototype has shown its correspondence to the requirements of the technical assignment. 


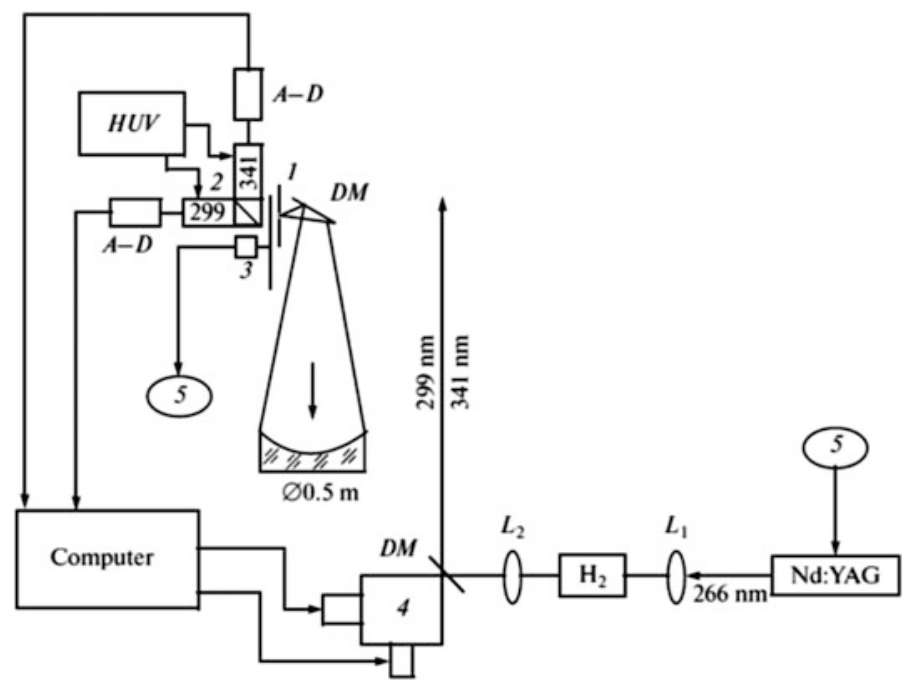

Fig. 8 Block diagram of ST Ozone lidar: Field stop (1), cell for spectral selection (2), mechanical shutter (3), adjustment unit of an output rotating mirror (4); system for synchronizing (5); rotating mirrors (RM); solid-state laser (Nd:YAG); SRS conversion cell with $\mathrm{H}_{2}\left(\mathrm{H}_{2}\right)$, amplifiers/discriminators (AD); high-voltage power supply units for the PMT (HSU); lenses $\left(\mathrm{L}_{1}\right.$ and $\mathrm{L}_{2}$ )

(a)

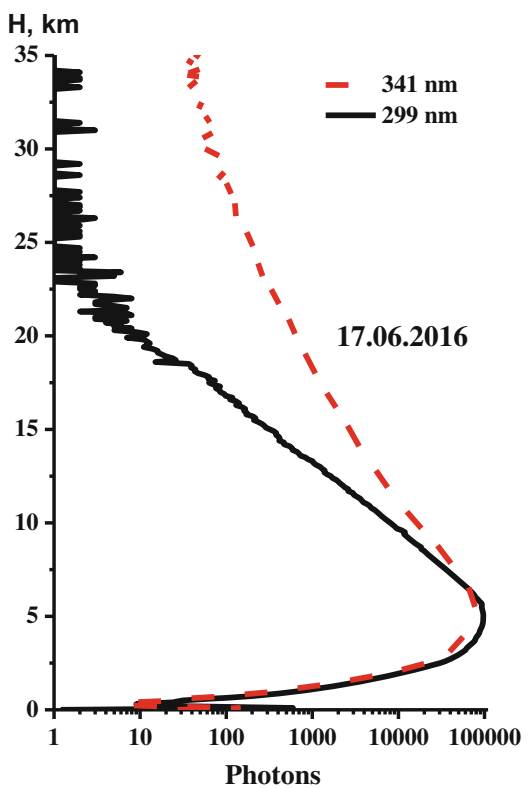

(b)

H, km

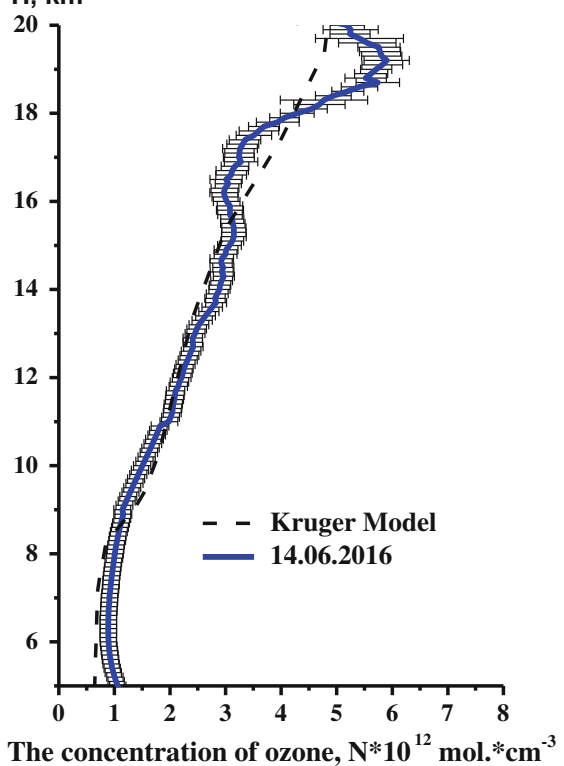

Fig. 9 (a) Lidar signals at 299/341 nm sounding wavelengths recorded at SLS in nighttime on June 14, 2016; (b) ozone vertical profile retrieved from signals (a) 


\section{Three-Channel Multifrequency Sodar}

The "Volna-4 M-ST" sodar has been designed for the prompt remote acoustic diagnosis of altitude profiles of the wind vector and absolute values of the structural parameters of the temperature field in the boundary air layer. The prototype of Volna-4 M-ST three-channel Doppler sodar has been manufactured and used for the monitoring of wind speed $U(H)$ and direction $\phi(H)$ profiles, as well as the structural parameter of the temperature field $C_{T}^{2}(H)$. The block diagram of the sodar is shown in Fig. 10.

The Volna-4 M-ST sodar was tested at the experimental site in building A of IAO SB RAS. Along with the sodar tests, signals of sodar poraboloid accelerometers, which control the radiated signal power, were recorded independently, and the acoustic pressure amplitude at the sodar receiver exit was measured. Using the check measurement results, the $C_{T}^{2}(H, t)$ profiles were calculated and then averaged and compared with the sodar measurement results. Figure 11 shows the averaged $C_{T}^{2}(H)$ profiles measured by sodar in 08:00-08:10 (June 10, 2016) and check calculated. The coincidence of the profiles for this period is quite satisfactory and corresponds to the requirements for the sodar measurement accuracy for $C_{T}^{2}(H)$.

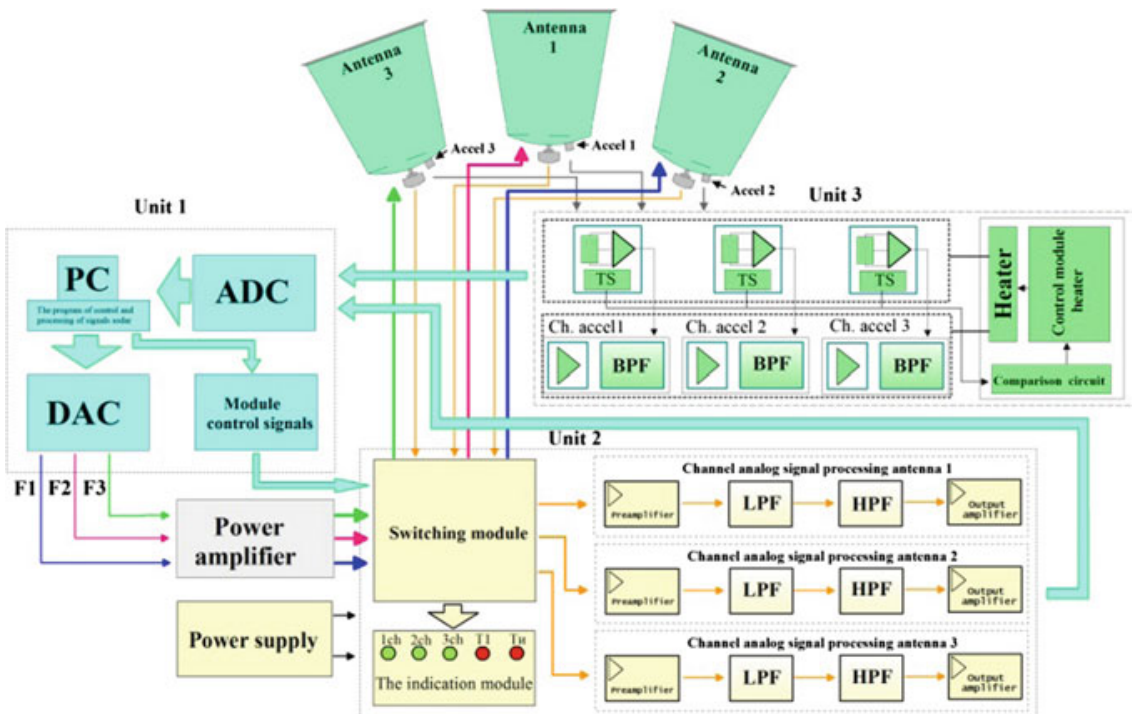

Fig. 10 Block diagram of the Volna-4M-ST sodar 
Fig. 11 Comparison of the 08:00-08:10 averaged (June 10, 2016) profiles of the air temperature structural parameter $C_{T}^{2}(H)$ measured by the sodar and retrieved

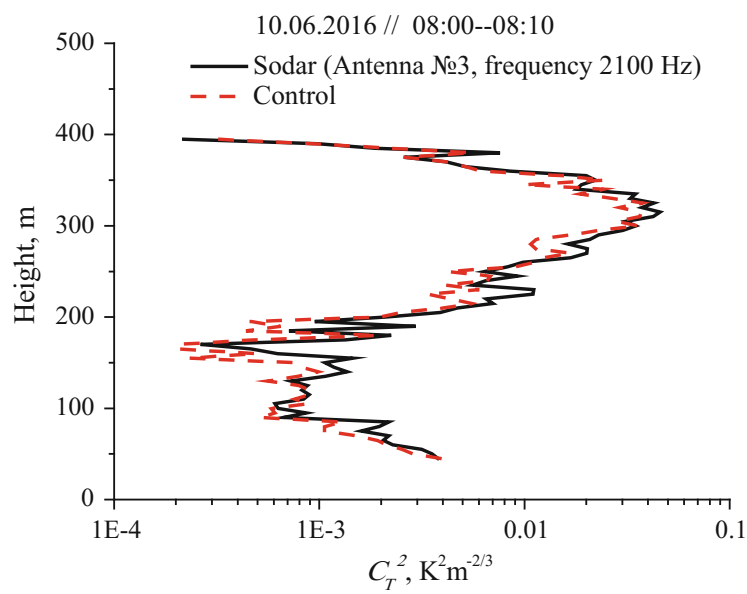

\section{Continuation of the Monitoring at Existing Stations and Setups}

During the project, atmosphere monitoring was carried out at all the available setups, including An-30 Optic-E and then Tu-134 Optic aircraft laboratories. During their flights, air was sampled in glass bulbs at altitudes of $0.5,1,1.5,2.0$, $3.0,4.0,5.5$, and $7 \mathrm{~km}$. The air samples were then analyzed at the laboratory of the National Institute for Environmental Studies (Japan) using the gas chromatography. The air sampling and measurements of the air gas composition have been carried out every month near 20s days under clear sky since July 1997. The sounding site is located to the southwest of Novosibirsk, to exclude the city effect. The flights are performed over the pine forest along the right bank of the Novosibirsk Reservoir, near Zyryanka and Ordynskoe settlements; they start at the point $\left(54^{\circ} 35^{\prime} \mathrm{N}, 82^{\circ} 40^{\prime}\right.$ E). A series of continuous measurements over more than 18 years is accumulated by now. Though there were unsuccessful flights, the series analyzed includes 200 vertical profiles of $\mathrm{CO}_{2}, \mathrm{CH}_{4}$, and $\mathrm{N}_{2} \mathrm{O}$ distributions. Figure 12 exemplifies long-term data on variations in the $\mathrm{CO}$ concentration over the region under study at altitudes of $0.5,3.0$, and $7.0 \mathrm{~km}$.

Figure 12 shows that the CO concentrations increased from 1997 to 2015 at all the altitudes. However, the increase has a peculiarity at an altitude of $0.5 \mathrm{~km}$ in summer. The CO concentration varied insignificantly from 1997 to 2005, and it started increasing in 2005 , even more rapid than at altitudes of 3.0 and $7.0 \mathrm{~km}$. 


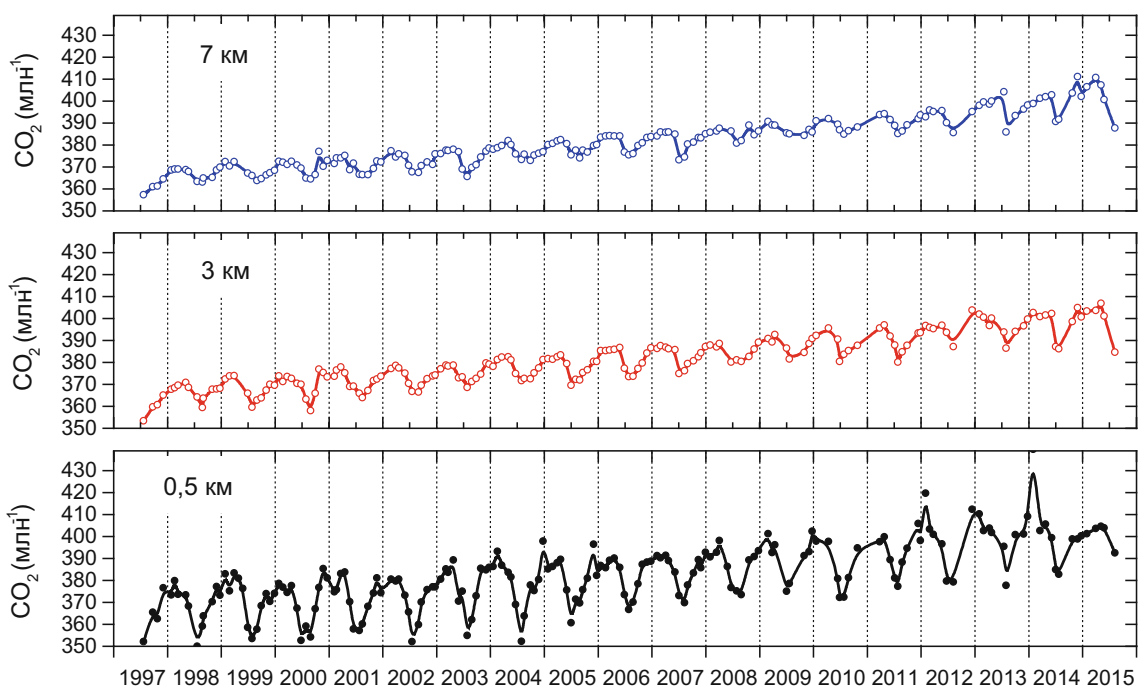

Fig. $12 \mathrm{CO}$ concentrations over south of Western Siberia at altitudes of $0.5,3.0$, and $7.0 \mathrm{~km}$

\section{Conclusions}

Instruments for the remote study of atmospheric composition and structure have been designed and tested within the project, including LOSA-M3, Aerosol-3, and ST Ozon lidars and Volna-4-ST sodar. The experimental examinations of the instruments confirmed the correspondence of their specifications and functional parameters to the technical assignment requirements. A typical automated station for monitoring the atmospheric composition and state and a multiwave diffusion spectrometer have also been designed and manufactured for contact measurements of air parameters. They also answer the technical assignment requirements. The project tasks include the continuation of air composition monitoring at currently operating setups. The measurement results showed the continuing increase in the carbon dioxide and nitrous oxide concentrations, as well as the renewed increase in the methane concentration in the layer from 0 to $7 \mathrm{~km}$.

Acknowledgements Research is carried out with the financial support of the state represented by the Ministry of Education and Science of the Russian Federation. Agreement (contract) no. 14.604.21.0100, July 16, 2014. Unique project Identifier: RFMEFI60414X0100. 


\section{References}

1. http://www.icos-infrastructure.eu

2. Matvienko, G.G., Belan, B.D., Panchenko, M.V. et. al.: Complex experiment on studying the microphysical, chemical, and optical properties of aerosol particles and estimating the contribution of atmospheric aerosol-to-earth radiation budget. Atmos. Meas. Tech. 8 (10), 4507-4520 (2015)

3. Kozlov, V.S., Shmargunov, V.P., Panchenko, M.V. et. al.: Seasonal variability of the black carbon size distribution in the atmospheric aerosol. Russ. Phys. J. 58 (12), 1804-1810 (2016)

4. http://www.iao.ru/en/resources/equip/lidars

Open Access This chapter is licensed under the terms of the Creative Commons Attribution 4.0 International License (http://creativecommons.org/licenses/by/4.0/), which permits use, sharing, adaptation, distribution and reproduction in any medium or format, as long as you give appropriate credit to the original author(s) and the source, provide a link to the Creative Commons license and indicate if changes were made.

The images or other third party material in this chapter are included in the chapter's Creative Commons license, unless indicated otherwise in a credit line to the material. If material is not included in the chapter's Creative Commons license and your intended use is not permitted by statutory regulation or exceeds the permitted use, you will need to obtain permission directly from the copyright holder.

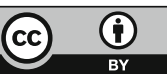

